\title{
MJFAS MALAYSIAN JUURNAL OF

\section{G-jitter fully developed heat transfer by mixed convection flow of nanofluid in a vertical channel}

\author{
Noraihan Afiqah Rawi, Wan Nor Zaleha Amin, Mohd Ariff Admon, Sharidan Shafie * \\ Department of Mathematical Sciences, Faculty of Science, Universiti Teknologi Malaysia, 81310 UTM Johor Bahru, Johor, Malaysia
}

* Corresponding author: sharidan@utm.my

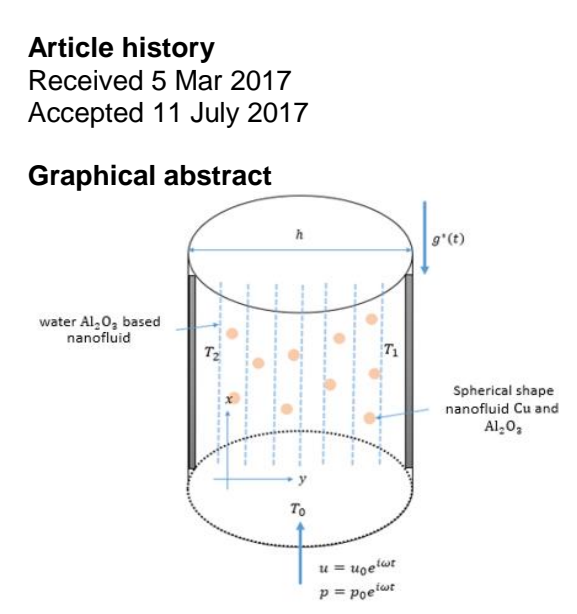

\begin{abstract}
In this study, the effect of g-jitter fully developed heat transfer by mixed convection flow of nanofluid in a vertical channel is investigated. The nanoparticles of aluminium oxide and copper with water as a base fluid are used in this study. The equations corresponding to this study are solved analytically to find the exact solutions. The results of velocity and temperature profiles with the influence of physical parameters such as mixed convection, oscillation, temperature ratio and volume fraction of the nanoparticles are plotted and analyze in details. The behaviour of steady state flow is also investigated. Results shown that as mixed convection, oscillation, and temperature ratio increased, the velocity profiles increased. The conductivity and viscosity of the nanofluid are also increased due to the increases of the volume fraction of nanoparticles in the water base fluid.
\end{abstract}

Keywords: G-jitter, heat transfer, mixed convection, nanofluid, analytical solution

\section{INTRODUCTION}

Free and mixed convection in vertical and inclined channels have received a great deal of attention in the literature. Mixed convection induced flow may occur in many applications, such as in heat exchangers, chemical processing equipment, transport of heated or cooled fluid, solar collectors and microelectronic cooling. Due to this reason, there are very extensive theoretical and experimental study of the problem during the last 60 years (Kostoglou et al., 2011). Previous research investigated on the flow behaviour about a heated sphere which is induced by g-jitter, and the effect of it (Amin, 1988). The investigation is focused on the effect of $\mathrm{g}$-jitter upon heat transfers from a sphere with a constant temperature. The researcher analyzed the modelling of g-jitter by simplify the governing equations of motion using certain dimensionless parameter of Reynolds number and analytically solved it by expanding the equations and matching the inner and outer solutions of boundary layer problems.

More importantly, the main focused of this research being conducted is to expand the following works which investigated the analytical study of g-jitter fully developed combined heat and mass transfer by mixed convection flow in a vertical channel (Sharidan et al., 2005). This system consists of two heated vertical parallel infinite flat plates held at constant but different temperatures. The governing equations are being transformed into non-dimensional form and solved analytically to find exact solutions for the induced velocity and temperature distribution.

Also, this research conducted by following a paper (Gul et al., 2015) which investigated the heat transfers in MHD mixed convection flow of a ferrofluids along a vertical channel. The resulting governing equation are transformed and solved using perturbation method. The graphical results presented the effect of radiation parameter, magnetic parameter and volume fraction of nanoparticles on velocity and temperature profiles.

The study of the fully developed heat transfer in nanofluid as well as to study the behaviour of g-jitter in a channel is very significant. However, this flow situation is not yet considered in any fluid flow research. Therefore, this project mainly focused on the study of the gjitter effect on fully developed heat transfer by mixed convection flow of nanofluid in a vertical channel. The main objectives of this research is to obtain theoretically the velocity profile of the mixed convection flow of nanofluid in a vertical channel influenced by g-jitter effect. It is required to develop the correct mathematical models by carry out the correct mathematical formulation of governing equations and choosing the right boundary conditions to solve the resulting equations analytically. The governing equations are solved analytically to obtained exact solutions of velocity and temperature profiles for copper $(\mathrm{Cu})$ and aluminium oxide $\left(\mathrm{Al}_{2} \mathrm{O}_{3}\right)$ with water $\left(\mathrm{H}_{2} \mathrm{O}\right)$ as the base fluid and to plot the obtained results for various dimensionless parameters.

For these recent years, there are numerous research based on flow of heat transfer in nanofluid due to its contribution and applications in many industrial and natural processes. This research conducted especially devoted to this matter. Application of mixed convection is often seen in very high power output devices where the forced convection is insufficient to transfer all of the heat necessary as a result of the nanofluid that enhancing the heat transfer process.

Considering this impact, present research is produced to prevent such nanoparticles cause problem like abrasion, clogging in the pipe flow, narrowing channel caused by plaques, arising temperature because of the fluid motion, eroding pipelines, an increase in pressure drop in practical application and others. Therefore, the purpose of this project is to give a better understanding on the behaviour of the fluid motion in a system, to study the volume fraction, types and properties 
of the nanoparticles that can affect the thermal conductivity of nanofluid and to enhance the knowledge of heat transfer that affect the wall transpiration in a channel.

\section{MATHEMATICAL MODEL}

In this study, water $\left(\mathrm{H}_{2} \mathrm{O}\right)$ based nanofluid containing aluminium oxide $\left(\mathrm{Al}_{2} \mathrm{O}_{3}\right)$ nanoparticles is considered. Pressure gradient of oscillatory type is applied in the flow direction. Copper $(\mathrm{Cu})$ nanoparticles is also used for comparison. The presence of g-jitter fully developed effect is also considered. Mixed convection flow exists between two vertical parallel plates with width, $h$ and uniform temperatures at the walls. By assuming at time, $t=0$, the flow is at the constant temperature, $T_{0}$ and has the mean velocity, $u_{0}$ and pressure, $p_{0}$. The assumption of fully developed flow means that the axial $(x-$ direction) velocity depends only on the transverse coordinate, $y$. Then, from continuity equation, the transverse velocity, $v$, must be zero. The axial velocity, $u$, and the fluid temperature, $T$, are assumed to be functions of $y$ plus functions of time, $t$. The pressure variation is found to be a linear function of $x$ and $t$, and we assume that the gravity acceleration is given by $g^{*}(t)=g_{0} \sin (\omega t)$ where $g_{0}$ is the magnitude and $\omega$ is the frequency of the g-jitter field.

Under the above assumptions, the unsteady mixed convection flow past an oscillating vertical plate is governed by the continuity equation, the equation of motion and the energy equation below.

$$
\begin{gathered}
\nabla \cdot \boldsymbol{u}=\frac{\partial u}{\partial x}+\frac{\partial v}{\partial y}+\frac{\partial w}{\partial z}=0 \\
\rho_{n f} \frac{\partial u}{\partial t}=-\frac{\partial p}{\partial x}+\mu_{n f} \frac{\partial^{2} u}{\partial y^{2}}+g^{*}(t)\left(\rho \beta_{T}\right)_{n f}\left(T-T_{0}\right), \\
\frac{\partial T}{\partial t}=\frac{k_{n f}}{\left(\rho c_{p}\right)_{n f}} \frac{\partial^{2} T}{\partial y^{2}} .
\end{gathered}
$$

These equations are subjected to boundary conditions

$$
\begin{gathered}
u(0, t)=0, u(h, t)=0, \\
T(0, t)=T_{1}, T(h, t)=T_{2}
\end{gathered}
$$

where $\mu_{n f}$ is the dynamic viscosity of the nanofluid, $\rho_{n f}$ is the fluid density of the nanofluid, $\left(\beta_{T}\right)_{n f}$ is the volumetric coefficient of thermal expansion of the nanofluid, $p$ is the fluid pressure, $k_{n f}$ is the thermal conductivity of the nanofluid, $\left(c_{p}\right)_{n f}$ is the specific heat of the nanofluid of the constant pressure, $h$ is the width of the channel and $T_{1}, T_{2}$ are the temperatures of the right and left wall, respectively which are given by (Oztop and Abu-Nada, 2008)

$$
\begin{gathered}
\mu_{n f}=\frac{\mu_{f}}{(1-\emptyset)^{2.5}} \\
\rho_{n f}=(1-\emptyset) \rho_{f}+\emptyset \rho_{s} \\
\left(\rho \beta_{T}\right)_{n f}=(1-\emptyset)\left(\rho \beta_{T}\right)_{f}+\emptyset\left(\rho \beta_{T}\right)_{s} \\
\left(\rho c_{p}\right)_{n f}=(1-\emptyset)\left(\rho c_{p}\right)_{f}+\emptyset\left(\rho c_{p}\right)_{s} \\
\frac{k_{n f}}{k_{f}}=\frac{\left(k_{s}+2 k_{f}\right)-2 \emptyset\left(k_{f}-k_{s}\right)}{\left(k_{s}-2 k_{f}\right)+\emptyset\left(k_{f}-k_{s}\right)}
\end{gathered}
$$

where $\varnothing$ is the nanoparticles volume fraction. The subscripts " $f$ " and "s" refer to base fluid and solid nanoparticles respectively.

The problem is then transformed into the following nondimensional equations

$$
\begin{gathered}
\emptyset_{1} \frac{\partial U}{\partial \tau}=-\frac{\partial P}{\partial X}+\emptyset_{2} \frac{\partial^{2} U}{\partial Y^{2}}+\frac{G r}{R e} \emptyset_{1} \cdot g(\tau) \cdot \theta, \\
\frac{\partial \theta}{\partial \tau}=\frac{1}{P r} \frac{\partial^{2} \theta}{\partial Y^{2}}
\end{gathered}
$$

where the non-dimensional variables are defined as with

$$
\begin{gathered}
U=\frac{u}{u_{0}}, \tau=\frac{v t}{h^{2}}, P=\frac{h p}{\rho v u_{0}}, X=\frac{x}{h}, Y=\frac{y}{h}, \\
\theta=\frac{T-T_{0}}{T_{2}-T_{0}}, g(\tau)=\frac{g^{*}}{g_{0}}
\end{gathered}
$$

$$
\emptyset_{1}=(1-\emptyset)+\emptyset \frac{\rho_{s}}{\rho_{f}}, \emptyset_{2}=\frac{1}{(1-\emptyset)^{2.5}}
$$

and Grashof number, $G r$, Reynolds number, $R e$ and Prandtl number, $\mathrm{Pr}$ are given by

$$
G r=\frac{g_{0} \beta_{T}\left(T_{2}-T_{0}\right) h^{3}}{v^{2}}, \operatorname{Re}=\frac{u_{0} h}{v}, \operatorname{Pr}=\frac{v\left(\rho c_{p}\right)_{n f}}{k_{n f}} .
$$

Then, the boundary conditions (4) become

$$
\begin{array}{ll}
U=0, \theta=r_{T} & \text { on } Y=0 \\
U=0, \theta=1 & \text { on } Y=1
\end{array}
$$

where the parameter of temperature, $r_{T}$ is defined as

$$
r_{T}=\frac{T_{1}-T_{0}}{T_{2}-T_{0}}
$$

Now, using separation of variables method, Eq. (7) have the solution of

$$
\theta(Y, \tau)=\left(1-r_{T}\right) Y+r_{T} .
$$

Next, Eq. (6) is solved using method of superposition. Assume $U=$ $e^{i \Omega \tau} \cdot \Phi(Y), P=e^{i \Omega \tau} \cdot F(X)$ and $g(\tau)=e^{i \Omega \tau}$ (Sharidan et al., 2005). Thus, Eq. (6) becomes

$$
\begin{aligned}
\emptyset_{1} i \Omega e^{i \Omega \tau} \Phi= & -\frac{\partial F}{\partial X} e^{i \Omega \tau}+\emptyset_{2} \Phi^{\prime \prime} e^{i \Omega \tau} \\
& +\frac{G r}{R e} \emptyset_{1} \cdot e^{i \Omega \tau} \cdot\left[\left(1-r_{T}\right) Y+r_{T}\right]
\end{aligned}
$$

along with the boundary conditions

$$
\Phi(0)=0, \Phi(1)=0 .
$$

Further, the condition of conservation of mass is defined as

$$
\int_{0}^{1} \Phi(Y) d Y=1
$$

The general solution of $\Phi(Y)$ becomes

$$
\begin{aligned}
\Phi(Y)=\frac{1}{\emptyset_{2} m_{1}^{2}}\{( & \left.\frac{\partial F}{\partial X}-\frac{G r}{R e} \emptyset_{1}\left[r_{T}\right]\right) \frac{\sinh \left(m_{1}(1-Y)\right)}{\sinh m_{1}} \\
+ & \left(\frac{\sinh m_{1} Y}{\sinh m_{1}}\left\{\frac{\partial F}{\partial X}-\frac{G r}{R e} \emptyset_{1}\right\}\right) \\
& \left.+\frac{G r}{R e} \emptyset_{1}\left[\left(1-r_{T}\right) Y+r_{T}\right]-\frac{\partial F}{\partial X}\right\}
\end{aligned}
$$

where $m_{1}{ }^{2}=\emptyset_{1} i \Omega / \emptyset_{2}$ with $\partial F / \partial X$ is given by

$$
\frac{\partial F}{\partial X}=\frac{\emptyset_{2} \cdot m_{1}^{3} \sinh m_{1}}{2 \cosh m_{1}-m_{1} \sinh m_{1}-2}+\frac{G r}{R e} \emptyset_{1}\left[\frac{1-r_{T}}{2}\right] \text {. }
$$

Now, for the case of steady flow where $\Omega=0$, the gravity field is constant. Therefore, for the case of steady flow, the solution is obtained as

$$
\Phi(Y)=\frac{G r}{\operatorname{Re}} \frac{\emptyset_{1}}{\emptyset_{2}}\left[\left(1-r_{T}\right)\left(-\frac{Y}{12}+\frac{Y^{2}}{4}-\frac{Y^{3}}{6}\right)\right]+6\left(Y-Y^{2}\right)
$$




\section{RESULTS AND DISSCUSSION}

In this paper, all the expressions of the solutions are being computed in the MATLAB software for illustrated the graphical result for all values of the physical parameters involved in the problem. The quantities plotted along the vertical axis are temperature and velocity profiles which the equations of solutions are

$$
\begin{gathered}
\theta(Y, \tau)=\left(1-r_{T}\right) Y+r_{T}, \\
\operatorname{Imag}\left(U=\Phi e^{i \Omega \tau}\right)=\operatorname{Real}(\Phi) \sin (\Omega \tau)+\operatorname{Imag}(\Phi) \cos (\Omega \tau)
\end{gathered}
$$

and it represent the value of driving force

$$
g^{*}(t)=\operatorname{Imag}\left(g_{0} e^{i \omega t}\right) \text { and } u_{0}(t)=u_{0} \sin (\omega t) .
$$

Table 1 shows the thermophysical properties of water and nanoparticles.

Table 1 Thermophysical properties of water and nanoparticles.

\begin{tabular}{cccc}
\hline $\begin{array}{c}\text { Physical } \\
\text { properties }\end{array}$ & $\begin{array}{c}\text { Base fluid } \\
\text { Water } \\
\left(\mathbf{H}_{\mathbf{2}} \mathbf{0}\right)\end{array}$ & $\begin{array}{c}\text { Solid Nanoparticles } \\
\text { Copper } \\
(\mathbf{C u})\end{array}$ & $\begin{array}{c}\text { Aluminium Oxide } \\
\left(\mathbf{A l}_{\mathbf{2}} \mathbf{O}_{\mathbf{3}}\right)\end{array}$ \\
\hline$c_{p}$ & 4179 & 385 & 765 \\
$\rho$ & 997.1 & 8933 & 3970 \\
$k$ & 0.613 & 401 & 40 \\
$\beta_{T}$ & 21 & 1.67 & 0.85 \\
\hline
\end{tabular}

Fig. 1 shows the variety of pattern with the effect of nondimensional wall temperature, $r_{T}$ in temperature equation. The different value of $r_{T}$ taken are in the range of $0 \leq r_{T} \leq 1$. The analytic result of temperature is given in Eq. (21). The graphical result shows that the value of $r_{T}$ is directly proportional to the temperature, $\theta(T)$. As $r_{T}$ increases, $\theta$ also increased.

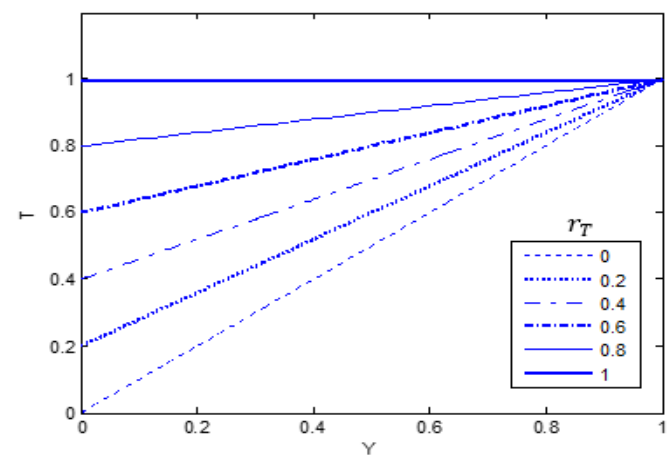

Fig. 1 Temperature profiles for different values of $r_{T}$

Fig. 2 - 7 considering the value of the volume fraction of solid nanoparticles, $\varnothing$ for aluminium oxide, $\mathrm{Al}_{2} \mathrm{O}_{3}$. Following (Gul et al., $2015)$, the value of $\varnothing$ is taken in the range of $0 \leq \emptyset \leq 0.04$. Note that, $\emptyset$ of the nanoparticles could not exceed $8 \%$ as sedimentation takes place in this range. Effect of $\emptyset$ on the flow water based nanofluid is studied. The parameters incorporated in the problem are $r_{T}, \Omega \tau, \Omega, \emptyset$ and $\mathrm{Gr} / \mathrm{Re}$.

The analysis on the effect of volume fraction, $\varnothing$ on the flow of water based nanofluid is investigated in Fig. 2. It is found that the velocity of the nanofluid increases when $\emptyset$ is increased. From the theoretical model (Yu and Choi, 2003), this result is valid because in Maxwell model, it defined that, the conductivity and viscosity of the nanofluid will increase due to the increased of the nanoparticle's volume fraction, $\emptyset$.

In Fig. 3(a) and (b), it is observed that there is only a small reversed flow closed to the right wall for $\mathrm{Gr} / \mathrm{Re}=30$ and only near to the left wall when $\mathrm{Gr} / \mathrm{Re}=300$, respectively. Meanwhile, in Fig. 4, for the different value of $r_{T}$, the velocity profile increases as $r_{T}$ increased. The flow is reversed close to the left wall as $r_{T}$ increased. For all cases, the streamwise velocity profiles are symmetric about the centerline of the channel where $Y=0.5$.

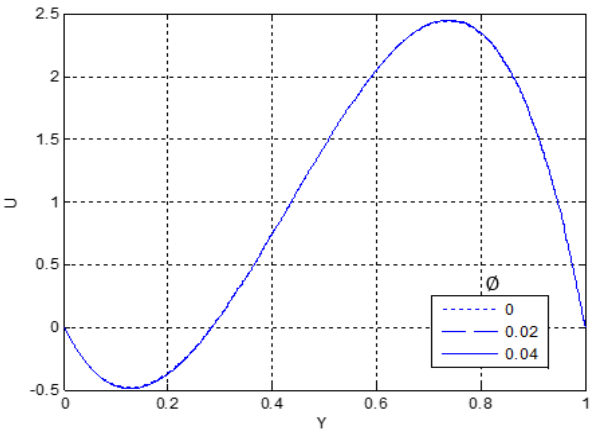

Fig.2 Velocity profiles of $\mathrm{Al}_{2} \mathrm{O}_{3}$ for different values of $\emptyset$ in water base fluid with $\mathrm{r}_{T}=0.3, \Omega \tau=\pi / 2, \Omega=10$, and $\mathrm{Gr} / \mathrm{Re}=300$.

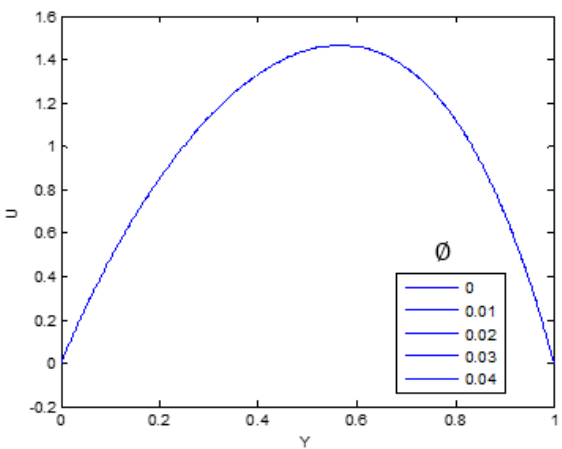

(a)

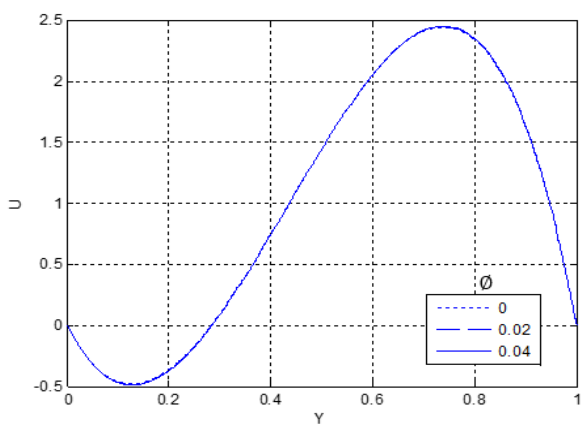

(b)

Fig.3 Velocity profiles of $\mathrm{Al}_{2} \mathrm{O}_{3}$ for different values of $\emptyset$ in water base fluid with $r_{T}=0.3, \Omega \tau=\pi / 2, \Omega=10$; a) $\mathrm{Gr} / \mathrm{Re}=30$; b) $\mathrm{Gr} / \mathrm{Re}=300$.

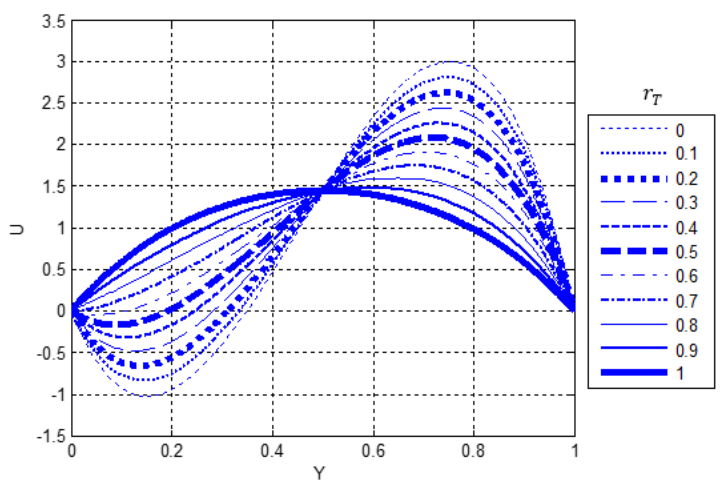

Fig. 4 Velocity profiles of $\mathrm{Al}_{2} \mathrm{O}_{3}$ for different values of $r_{T}$ in water base fluid with $\mathrm{Gr} / \operatorname{Re}=300, \Omega \tau=\pi / 2, \Omega=10, \emptyset=0.02$.

Further, Fig. 5 illustrated the different values of mixed convection, $\mathrm{Gr} / \mathrm{Re}$ for 30 and 300 . The result shows that there is only a small reversed flow close to the right wall for $\mathrm{Gr} / \mathrm{Re}=30$ in Fig. 5(a) but it increases when $\mathrm{Gr} / \mathrm{Re}=300$ in Fig. 5(b). On the other hand, there is full reversed flow for some values of $\Omega \tau$ in Fig. 5(a) and partial reversed flow when Gr/Re increased. In Fig. 5(b), the flow is not anymore symmetric about $Y=0.5$. It can be concluded that, as $\Omega \tau$ increases, the velocity fluctuated. 


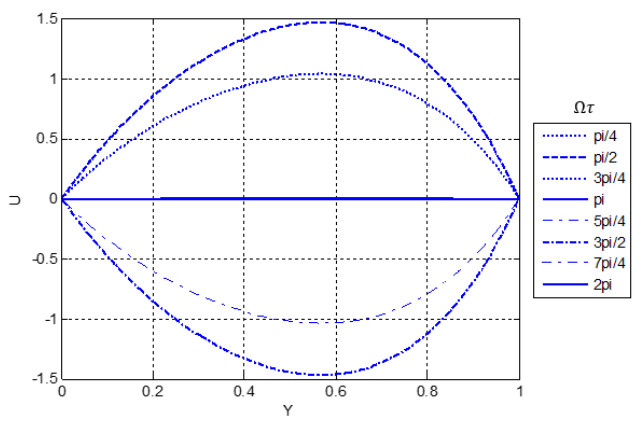

(a)

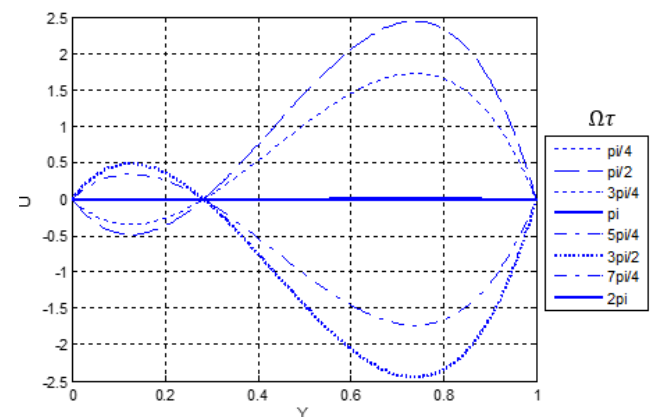

(b)

Fig. 5 Velocity profiles of $\mathrm{Al}_{2} \mathrm{O}_{3}$ for different values of $\Omega \tau$ in water base fluid with $r_{T}=0.3, \Omega=10, \varnothing=0.02$; (a) $\mathrm{Gr} / \mathrm{Re}=30$; (b) $\mathrm{Gr} / \mathrm{Re}=300$.

Fig. 6 (a) and (b) shows a comparison of velocity when two different type of nanoparticles which are aluminium oxide, $\mathrm{Al}_{2} \mathrm{O}_{3}$ and Copper, $\mathrm{Cu}$ added to the convectional water, $\mathrm{H}_{2} \mathrm{O}$ base fluid. The result shows that velocity of the $\mathrm{Cu}$ is higher than $\mathrm{Al}_{2} \mathrm{O}_{3}$ in $\mathrm{H}_{2} \mathrm{O}$ base fluid with $\phi=0.02$. Therefore, this shows that the thermal conductivity and dynamic viscosity of $\mathrm{Cu}$ is higher than $\mathrm{Al}_{2} \mathrm{O}_{3}$ in water.

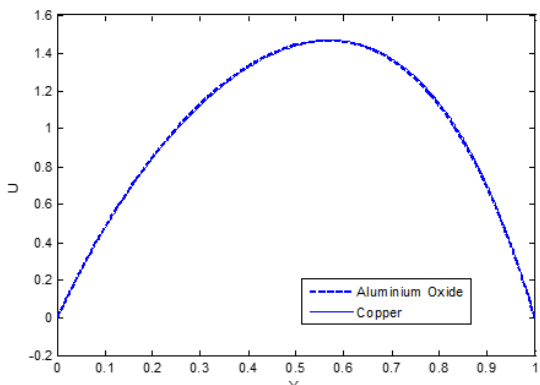

(a)

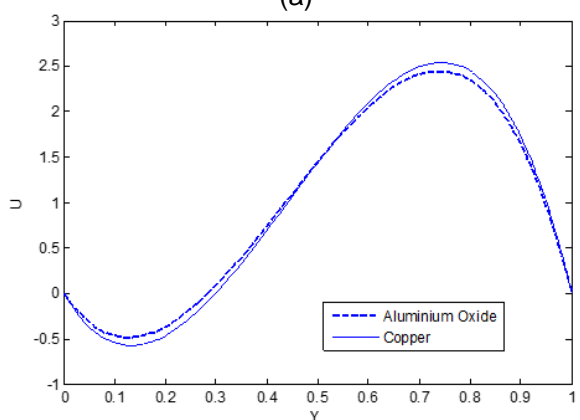

(b)

Fig. 6 Comparison of velocity profiles between $\mathrm{Cu}$ and $\mathrm{Al}_{2} \mathrm{O}_{3}$ in water base fluid with $r_{T}=0.3, \Omega \tau=\pi / 2, \Omega=10, \emptyset=0.02$; (a) $\mathrm{Gr} / \operatorname{Re}=30$; (b) $\mathrm{Gr} / \mathrm{Re}=300$.

Finally, for the case of steady flow where, $\Omega=0$, Eq. (20) was computed and presented graphically as shown in Fig. 7(a) and (b). The result shows that the velocity profile is always symmetric about the centerline of the channel where $Y=0.5$. From the result, it can be concluded that as the non-dimensional wall temperature parameter, $r_{T}$ increases, the velocity also increased. It can also be concluded that the thermal conductivity and dynamic viscosity increases when $r_{T}$ increased.

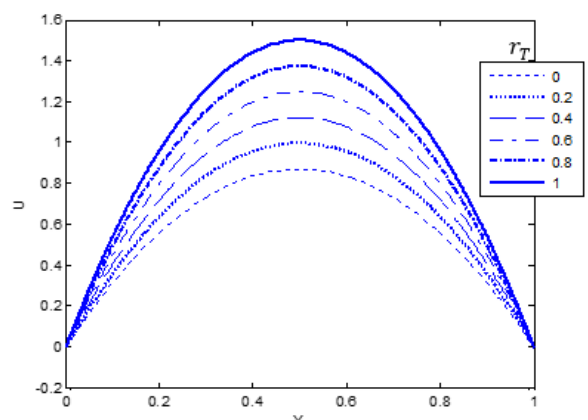

(a)

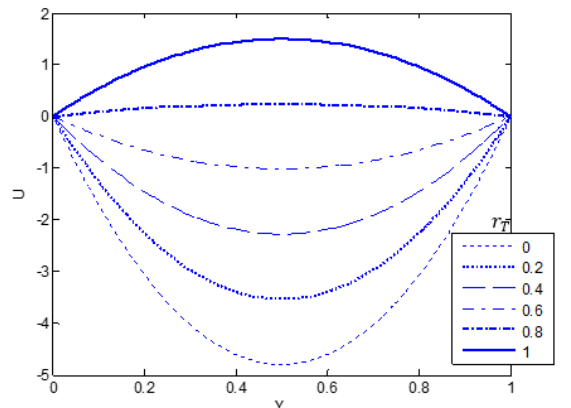

(b)

Fig. 7 Steady state velocity profiles of $\mathrm{Al}_{2} \mathrm{O}_{3}$ for different values of $r_{T}$ in water base fluid with $\emptyset=0.02, h=0.1$; (a) $\mathrm{Gr} / \mathrm{Re}=30$; (b) $\mathrm{Gr} / \mathrm{Re}=300$.

\section{CONCLUSION}

Overall, the research findings regarding to research objectives can be summaries as the presence of nanofluid will affect the velocity flow of a fluid which is higher in term of heat transfer. The non-dimensional wall temperature, $r_{T}$ is directly proportional to the temperature which means the temperature, $\theta$ increase when the non-dimensional wall temperature, $r_{T}$ increased. The conductivity and viscosity of the nanofluid will also increase due to the increases of the volume fraction, $\emptyset$ of nanoparticles in the base fluid. Meanwhile, the velocity, $U$ fluctuated as the oscillating parameter, $\Omega \tau$ increased. The velocity, $U$ increases as $r_{T}$ and $\mathrm{Gr} / \mathrm{Re}$ increased. For the different types of nanoparticles used, the thermal conductivity and viscosity of $\mathrm{Cu}$ is higher than $\mathrm{Al}_{2} \mathrm{O}_{3}$ in $\mathrm{H}_{2} 0$. For the case of steady flow, the velocity, $U$ increases as $r_{T}$ increased.

\section{ACKNOWLEDGEMENT}

The authors would like to acknowledge Ministry of Higher Education (MOHE) and Research Management Centre-UTM for the financial support through vote numbers 4F713, 15H80 and $13 \mathrm{H} 74$.

\section{REFERENCES}

Amin, N. 1988. The effect of g-jitter on heat transfer. Proceedings of the Royal Society of London A: Mathematical, Physical and Engineering Sciences, 151172.

Gul, A., Khan, I., Shafie, S., Khalid, A., Khan, A. 2015. Heat transfer in MHD mixed convection flow of a ferrofluid along a vertical channel. Plos One, 10, $1-14$.

Kostoglou, M., Evgenidis, S. P., Zacharias, K. A., Karapantsios, T. D. 2011. Heat transfer from small objects in microgravity: experiments and analysis. International Journal of Heat and Mass Transfer, 54, 3323-3333.

Oztop, H. F., Abu-Nada, E. 2008. Numerical study of natural convection in partially heated rectangular enclosures filled with nanofluids. International Journal of Heat and Fluid Flow, 29, 1326-1336.

Sharidan, S., Amin, N., Pop, I. 2005. G-jitter fully developed combined heat and mass transfer by mixed convection flow in a vertical channel. International Communications in Heat and Mass Transfer, 32, 657-665.

Yu, W., Choi, S. 2003. The role of interfacial layers in the enhanced thermal conductivity of nanofluids: a renovated Maxwell model. Journal of Nanoparticle Research, 5, 167-171. 